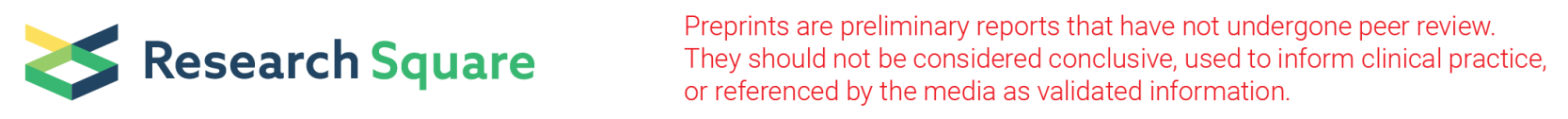

\title{
Development of a competency model for general practitioners in China by a modified Delphi method
}

Yun Wei

Capital Medical University

Feiyue Wang

Capital Medical University

Zhaolu Pan

Capital Medical University

Meirong Wang

Capital Medical University

Guanghui Jin

Capital Medical University

Yanli Liu

Beijing Tian Tan Hospital

Xiaoqin Lu ( $\square$ cumsfmxq@ccmu.edu.cn )

Capital Medical University

\section{Research Article}

Keywords: China, competency, Delphi method, general practitioner, training

Posted Date: March 30th, 2021

DOI: https://doi.org/10.21203/rs.3.rs-319609/v1

License: (c) (i) This work is licensed under a Creative Commons Attribution 4.0 International License. Read Full License 


\section{Abstract \\ Background.}

General practitioner training in China has gradually been structured into a " $5+3$ " residency training model. However, no competency model for general practitioners is implemented to evaluate the level of clinical competence attained by general practice trainees. This study was conducted to develop a consensus set of competencies for general practitioners in China.

\section{Methods.}

A modified Delphi process was deployed to develop the competency model for general practitioners in China, including two stages: (1) generation of an initial set of relevant competencies derived from a literature review, behavioral observation of GP-patient consultations, and critical incidents interview of GPs; (2) a 2-round, web-based Delphi survey of experts in general practice, selected using purposive sampling, to prioritize and gain consensus on the essential competencies of GPs.

\section{Results.}

From the literature review, behavioral observation, and critical incidents interview, 46 competencies in 7 domains were identified. After two rounds of Delphi survey of 28 participants (18 [64.3\%] women; mean [SD] age, 47.9 [9.3] years) representing a range of health professionals (GPs, managers, and researchers), a consensus was reached on 50 competencies categorized into 7 domains.

\section{Conclusion.}

A consensus-based competency model for general practitioners in China has been identified that may be used to evaluate the general practitioners' clinical competence after standardized training.

\section{Background}

Primary health care (PHC) plays a very crucial role in high-performing health care system. In recent years, hospital-centric health delivery system was popular in China, in which patients preferred to get medical services in large public tertiary hospitals rather than PHC institutions, leading to a perception of health services as "too difficult to access and too expensive" [1]. Therefore, several policies has been introduced to improve PHC system in China to provide citizens with affordable and equitable access to basic health care [2-4]. In 2019, Chinese government invested $¥ 215$ billion to PHC institutions [5], increasing by nearly eightfold from $¥ 27$ billion in 2009 [6]. With the strong support of the government, the primary care network was mostly developed around China. According to statistics in 2019, there were 954,390 PHC institutions across China, with 4.53 billion PHC visits in that year (accounting for $52.0 \%$ of the total visits) [7], increasing by $58.9 \%$ compared to the PHC visits in 2009 [8].

High-quality professionals are an integral part of the development of PHC. General practitioners (GPs), the core of PHC, are often referred to as "gatekeepers." A novel model called the GP team was promoted in China in 2011, in which, GPs, nurses, and, sometimes, public health doctors work as a team to provide continuous and comprehensive medical services to enrolled residents [9]. At the same time, the State Council advised that GP system should be established and GP training scheme should be structured into " $5+3$ " mode (GPs should receive 5-year undergraduate-level clinical medical education, followed by 3-year post-graduate GP standardized training) [10]. According to statistics in 2019, there were 365,000 GPs in China, with 2.61 GPs for per ten thousand residents [6], which has achieved the goal of at least 2-3 GPs per ten thousand residents in $2020[10,11]$.

Recently, promoting professionalism has become an explicit objective in GP training. Evaluation of professional competence is a vital element of this initiative. Professional competence in medicine was defined as "the habitual and judicious use of communication, knowledge, technical skills, clinical reasoning, emotions, values, and reflection in daily practice for the benefit of the individual and community being served" by Epstein and Hundert in JAMA [12]. There were practical competency models in developed countries, such as the European Definition of General Practice/Family Medicine in Europe [13], CanMEDS-FM 2017 in Canada [14], The Family Medicine Milestone Project in US [15], Workplace Based Assessment and Annual Review of Competence Progression guidance in UK [16], and Competency profile of the Australian general practitioner at the point of fellowship in Australia [17]. These competency models were used to evaluate the GPs' professional performance in the workplace. 
As the functions of PHC institutions in China include providing generalist care and implementing the National Basic Public Health Services Program [18], the role of the GP in China was different from the counterparts in other countries. Many researchers in China had tried to explore the competencies required for the role of GP in China. A literature review of 31 studies evaluating competencies of GPs in China, conducted by our research team before this research, found that more than half of the included studies did not develop a psychometrically robust, highquality instrument and no competency model was intended to be used in standardized training [19]. As the competency-based training model was embraced in China, the evaluation of competency was an important part of training program. In response to this need, this research was conducted to develop a competency model required for the occupation of GP.

\section{Methods}

\section{Design}

This was a study developing of competency model for general practitioners through a modified Delphi method. The Delphi method is a structured process for consensus-building among a diverse group of experts. The approach has commonly been adopted in medical research [20] and remains today the most widely used method for selecting quality indicators in healthcare [21]. The process ends when an agreement has been reached on the discussed topics. According to the previous studies, two or three rounds are frequently used in the Delphi process [22-23]. This study involved two rounds of questionnaires to an expert panel via e-mail from September to November 2020. All methods in the Delphi process were carried out in accordance with previous studies [22-24] and research guideline for the Delphi survey technique [25].

This modified Delphi process was deployed based on two stages: (1) generating an initial set of relevant competencies derived from a literature review, behavioral observation of GP-patient consultations, and critical incidents interviews of GPs; (2) conducting a 2-round, webbased Delphi survey of experts in general practice to prioritize and gain consensus on the essential competencies of GPs. Please see Figure 1 for the process of the Delphi study.

\section{Participants}

A list of eligible experts was initially selected considering the representation of all potential differences in background, occupational environment and clinical practices. The experts were invited based on the following inclusion criteria: (1) working as GP, educator, or administrative leader in general practice department; (2) having at least 5 years' working experience in general practice; (3) being familiar with requirement of GP; (4) being familiar with " $5+3$ " residency training; (5) being from various geographic regions within China. The participants were asked for their willingness to take part in the study. In a preliminary recruitment round, 30 eligible experts were invited to participate in the study and 28 experts agreed to participate.

\section{Questionnaire preparation}

The potential competencies were generated based on a literature review, behavioral observations, and critical incidents interviews.

\section{Literature review}

A preliminary list of competencies was constructed from three sources by literature review. Firstly, literature was searched in PubMed, EMBASE, Google-Scholar and three Chinese databases (China National Knowledge Infrastructure, Wanfang Data, VIP Chinese Periodical Services) with terms commonly used to describe GP (e.g., general practitioner, family physician, family doctor, community health worker), competency (e.g., competency, competencies, core competencies) and evaluation (e.g., evaluation, measurement, tool, indicator). A total of 37 published research papers describing domestic and foreign GPs' competencies were identified form literature review. Secondly, 5 published competency model from international general practice organizations were also identified, including: the World Organization of Family Doctors (WONCA) [13], the College of Family Physicians of Canada (CFPC) [14], the Accreditation Council for Graduate Medical Education (ACGME) [15], the Royal College of General Practitioners (RCGP) [16], the Royal Australian College of General Practitioners (RACGP) [17]. Thirdly, 2 published policy documents of residency training content and requirement of GP in China were reviewed [26,27].

Potential competencies were extracted from these sources and screened by a panel of 2 reviewers (YW and FYW, Ph.D. candidates) according to the following criteria: (1) the indicator was relevant to requirements of GPs in China; (2) the indicator was measurable. When there were doubts about whether an indicator should be retained, the research team would discuss together to make a decision. There were 88 competencies identified by the screening process.

\section{Behavioral observation}

Eleven GPs from 5 community health service institutions (CHSIs) in Beijing were invited to participate based on a convenience sample. Participating GPs were observed when providing medical care in the general practice consultations with each GP for one workday during 
November 2019 to January 2020. All consecutive patients visiting the recruited GPs on the observing workday were recruited in our study with oral agreement. During the observation, the information was recorded which including patients' reasons for encounter (RFEs) and medical services provided by GPs. Three research assistants (YW, FYW, and ZLP, Ph.D. candidates) were hired as observers who were postgraduate students, majored in general practice and had a training session before the observation. During the observation, the observers were seated in the least intrusive corner of consulting room and will not talk to the GPs and patients. There were 21 competencies related to GPs' work content were identified by the behavioral observation process.

\section{Critical incidents interview}

The same 11 GPs as in behavioral observation were invited and 8 GPs participate in the critical incidents interview. Of those three declined, the reasons was that individuals invited to participate were unable to attend for practical and/or domestic reasons. During the interview, participants were asked to describe incidents with good effect and incidents with bad effect. Questions were asked based a "STAR Principle", which included 'What kind of situation was it at that time?' (Situation), 'What was the main task you faced at that time?' (Task), 'In that incident, what skills did the you display?' (Action), 'What was the final result of this incident?' (Result). The information from incident interview was taped, transcribed, and coded. Three researchers (YW, FYW, and ZLP, Ph.D. candidates) extracted the information about GPs' competencies from the incident interview data respectively. When there were doubts about whether a description of competency should be retained, the research team would discuss together to make a decision. There were 35 competencies were identified by the critical incidents interview process.

A total of 144 competencies were identified by these three processes above. After deleting the duplicate competencies and integrating the competencies with similar dimensions being measured, a preliminary list of 63 potential competencies were left. Then, the competencies were discussed in detail one by one in a research team meeting, concentrating on whether these competencies were measurable and wording them by referring to other competency models. After further removal and integration, 46 potential competencies were left, which were categorized into 7 domains.

\section{Delphi questionnaire}

All 46 potential competencies were formatted into the Delphi questionnaire. Importance and feasibility of the competencies were rated on a 19 Likert scale ( 1 = not important/feasible; 9 = very important/feasible). Spaces were left for experts to make comments on these existing competencies or recommend new competencies which they considered should be included in.

\section{Delphi survey}

First round. The first round of Delphi survey was performed from September to October 2020, lasting 4 weeks. Materials were sent to experts by e-mail, including first-round questionnaire, research background, and basic demographic information collection form. In the first-round questionnaire, experts were asked to rate the importance and feasibility of each competency, and give their comments.

After the first round of Delphi survey, data was collected and analyzed. The median scores, the distribution of scores (frequency count of answer choices), and comments were reported. For the experts' comments, including modification, deletion and addition, we sort out and make a summary of comments expressed by at least two participants.

Second round. The second round of Delphi survey was performed from October to November 2020, lasting 4 weeks. The second-round questionnaire was sent to experts who had completed the first-round questionnaire by e-mail. In the second-round questionnaire, the competencies which were achieved consensus level or modified based on comments in the first round were retained for Delphi round 2. New competencies were added based on the suggestion by more than two experts. Competencies were removed which did not achieved consensus level or was recommended to be removed by more than 2 experts. Along with the second-round questionnaire, the graph-based report of the results of the first round was also send to experts. Importance and feasibility of each competency were rated using the same 1-9 Likert scale as in the first round.

Consensus. There is no definite consensus criteria for the Delphi study [28]. In this study a consensus was reached based on two selection criteria: median score greater than seven on a nine-point scale and at least $75 \%$ of panel ratings in the top tertile (7-9) for importance and feasibility.

\section{Statistical analysis}

Descriptive analysis was used to describe the characteristics of participates and results. Means [with standard deviation (SD)] were used to report continuous variables, while frequencies (\%) were used to report categorical variables. The Data management and analysis were performed using Statistical Package for Social Science (SPSS), version 22.0. 


\section{Results}

\section{Panel characteristics in Delphi survey}

Of the 28 experts who agreed to participate in the study, all participated in both two rounds of Delphi survey. Among them, 21 experts were from Beijing, 2 experts were from Shanghai, and other 5 experts were from 5 provinces of China (Hainan, Zhejiang, Anhui, Hebei, Inner Mongolia). There were more female participants (64.3\%) in this panel, and the mean age of the experts was 47.9 years (standard deviation: 9.3 years). Nearly one third participants were working as GPs in CHSI, 39.3\% working as GPs in hospital, $10.7 \%$ were researchers in primary care,and $17.9 \%$ were leaders of $\mathrm{CHSI}$. The average length of general practice experience was 14.4 years, with $67.9 \%$ experts working for more than 10 years in this field. There were $78.6 \%$ experts had master or PhD degree and $64.3 \%$ experts were with senior grade title (Table 1 ).

\section{First round}

In the first round, 44 (95.7\%) of the original 46 competencies achieved good consensus in round one. The median score of competencies' importance and feasibility ranged from 8.00 to 9.00 and 7.00 to 9.00 , respectively. The percentage of panel ratings in the top tertile (7-9) for importance and feasibility ranged from $85.7 \%$ to $100 \%$ and $69.9 \%$ to $100 \%$, respectively. There were 2 competencies did not achieve $75.0 \%$ agreement in terms of feasibility, which were " 3.2 Screen of at risk individuals for population health issues" ( $69.9 \%$ agreement) and " 5.5 Allocate external resources of the institution for optimal patient care" (71.4\% agreement). The indicator "3.4 Provide chemoprevention care" was recommended to be removed by more than 2 experts, despite the agreement being achieved. So, three competencies were deleted in the first round.

Two descriptions of domains were modified. "2. Basic Medical Services" was modified into "2. Patient care". "3. Preventive care and basic public health service" was modified into "3. Basic public health service". Eight competencies $(1.10,2.3,2.7,2.8,3.7,4.1,4.5$, and 5.4) were modified based on the experts' comments. For example, "1.10 Record electronic health information" was modified into "1.10 Use electronic health record system effectively". New competencies were suggested by 13 of the 28 experts in the first round. Only 7 new competencies were suggested by more than two experts and hence included in the second round (Table 2). Thus, 50 competencies were included in the second round.

\section{Second round}

At this step, 50 competencies were evaluated, including retained, modified, and new competencies. In the second round, the median score of competencies' importance and feasibility ranged from 7.50 to 9.00 and 7.00 to 9.00 , respectively. The percentage of panel ratings in the top tertile (7-9) for importance and feasibility ranged from $85.7 \%$ to $100 \%$ and $82.1 \%$ to $100 \%$, respectively. As a result, more than $75 \%$ of the experts gave ratings in the top tertile (7-9) to 50 competencies, all of which had a median of 7 or above and a high degree of consensus was achieved in terms of importance and feasibility. Descriptive statistics including the median and percentage agreement for each indicator is shown in Table 2.

At the end of the Delphi process, 50 competencies were finally selected based on the consensus in second round and divided under 7 domains: knowledge and skills (10 competencies), patient care (9 competencies), basic public health services ( 6 competencies), communication (7 competencies), teamwork (6 competencies), professionalism (6 competencies) and education, learning and research (6 competencies) (Table 3).

\section{Discussion}

\section{Main finding}

This study was a rigorous process, which involved integrating evidence from a multi-method approach to analyze the behaviors associated with the performance of GP, including a literature review, behavioral observation of GP-patient consultation, and critical incidents interview of GP. Then a modified Delphi survey was conducted in 28 general practice experts, to achieve consensus on the most essential competencies of GPs, which should be feasible to measure in China. The final consensus set includes 50 competencies categorized into 7 domains.

As described previously, competency of GP involved many aspects, such as patient care, communication, professional knowledge and skills, professionalism and practice-based learning [13-17], which were also important for GPs' role in China. For example, the recognition that communication and empathy were derived from all job incumbents, which implies that these are important aspects of the job role [24]. The results in previous studies suggested that effective communication was crucial to doctor-patient relationship [29], and for general practice in particular, in which communication and empathy was essential in patient-centered care [30]. In competency model of GPs in China, communication with patients was emphasized as most competencies in this domain (5/7) being involved in doctor-patient communication. 
It is notable that there are three aspects special in China: basic public health service, teamwork, and research. To tackle health inequity, providing universal basic public health services for residents is the main goal of the new health reform in China. Since 2009 , basic public health services programs have been widely carried out across PHC sectors in China [31], which now includes 14 categories, such as health records management for residents, health education, vaccination, reporting of infectious diseases and public health emergencies, and etc. [18]. GPs in PHC system play key roles in delivering majority of basic public health services. Therefore,we made an attempt to identify competencies in this domain on the basis of basic public health services programs and the experts' consensus. Six competencies were emphasized as an independent domain "3. Basic public health service". Since 2011, many provinces and cities in China have explored mode of "family doctor contract" services, which help to let patients have their personal doctors and improve the continuity of care based on GP team with a GP, a nurse, and a preventive care physician [32]. In that case, the ability of working effectively with others in a collaborative teambased model is emphasized to GPs in China. Besides, the collaborative leadership is also an important indicator as GP plays the role of leader in the team. In China, research ability and paper are critical to physicians in career advancement. During the standardized training program, GPs can be trained with the ability of scientific research [26], which should be evaluated. Therefore, three competencies were included in our competency model according to experts' opinion.

The development of appropriate assessment tools to evaluate the GPs' competencies is challenging in China. A literature review of 31 studies evaluating competencies of GPs in China, conducted by our research team before this research, found that more than half of the included studies did not use a psychometrically robust, high-quality instrument to measure their outcomes [19]. In this study, we organized the Delphi questionnaire that encompassed previous studies regarding GP competencies and published competency model from international general practice organizations [13-17]. Then, further competencies related to the work content of GPs were added by behavioral observation of GPpatient consultations and critical incidents interview of GPs. The results could be expected as some competencies are only identifiable by the job holders or are directly observed by the third party during the GP-patient consultation process. By means of these methods, which were adopted in previous study in England [24], more comprehensive competencies have been developed. This competency model marks a major improvement on previous research.

In this Delphi process, the importance and the feasibility of the competencies were both rated and finally achieved the consensus. This set of competencies just provide a basis for the competency measurement of GPs in China, which still needs to be tested in practice in a further study [33]. We suggest compiling these competencies in our model into a questionnaire for self-evaluation by GPs or multi-source assessment by other staff of GPs [34].

\section{Strengths and limitations}

The quality of the panel experts and their opinions on the given topic is seen as strength of the Delphi technique [35]. In this study, the presence of different fields (GPs in hospitals, GPs in CHSIs, leaders of CHSIs, and researchers in universities) and different geographical contexts (28 experts from 7 provinces of China), along with the average length of general practice experience (14.4 years), suggested that our expert panel represented a broad and experienced group. Furthermore, the response rate of our study was satisfactory, namely $100 \%$ in two rounds of Delphi process. This was a pleasing result as response rate was a recognized problem in Delphi study. Importantly, this meant that experts had much interest and active participation in this topic.

There are limitations of this study. First, although experts in this study were from different geographical contexts, most were from Beijing and the proportion of experts in other provinces was unsatisfactory. They may not adequately represent the full spectrum of views held by individuals in various regions across China. Second, patients' opinion was not involved in the sources of competency. Patients are the customers and beneficiaries of general practice services, who may give a deeper insight in health care experience and doctor-patient communication [24]. This should be taken into consideration in further study. Last, this methodology of Delphi process is relies on the perception of experts, which may influence the implementation for lacking actual evidence from real implementation [36]. Further study is needed to apply this competency model and confirm the validity of these competencies.

\section{Conclusion}

Based on a systematic consensus process, the competency model of GPs in China has been developed and described. Self-evaluation and multi-source feedback were recommended to use this model in exploring GPs' clinical performance and professional behaviour. Before putting it into practice, this competency model still need to be validated in a further study.

\section{Declarations}

\section{Authors' contributions}


YW and XQL designed the study. XQL obtained funding and ethical approval. YW, FYW, ZLP, MRW, and YLL were responsible for the indicator generation and Delphi survey process and statistical analyses. YW drafted the manuscript. GHJ and XQL contributed to the interpretation of the results and critical revision of the manuscript for important intellectual content and approved the final version of the manuscript. All authors have read and approved the final manuscript.

\section{Ethics approval and consent to participate}

This study was approved by the Ethical Committee of Capital Medical University, Beijing, China. Written informed consents were achieved from all the participants in this study. The participants were assured that their information would only be used for analysis in this study.

\section{Funding}

This work was supported by the Capital General Practice Research Project (17QK06). The funding organization had no role in the design, conduct, analysis and interpretation or preparation of this study.

\section{Acknowledgements}

The authors thank the Capital General Practice Research Project (17QK06) for the support. The authors also thank all of the participants for their support and help to our research.

\section{Availability of data and materials}

The data used and/or analyzed during the current study are available from the corresponding author on reasonable request.

\section{Consent for publication}

Not applicable.

\section{Competing interests}

The authors declare that they have no competing interests.

\section{Abbreviations}

PHC, primary health care; GPs, General Practitioners; WONCA, the World Organization of Family Doctors; CFPC, the College of Family Physicians of Canada; ACGME, the Accreditation Council for Graduate Medical Education; RCGP, the Royal College of General Practitioners; RACGP, the Royal Australian College of General Practitioners; CHSI, community health service institution; RFEs, reasons for encounter.

\section{References}

1. Li H, Liu K, Gu J, Zhang Y, Qiao Y, Sun X. The development and impact of primary health care in China from 1949 to 2015: A focused review. Int J Health Plann Manage. 2017;32(3):339-350. doi:10.1002/hpm.2435

2. Chen Z. Launch of the health-care reform plan in China. Lancet. 2009;373(9672):1322-1324. doi:10.1016/S0140-6736(09)60753-4

3. State Council of the People's Republic of China. Opinions on deepening the health care reform [in Chinese]. 2009. http://www.gov.cn/jrzg/2009-04/06/content_1278721.htm. Accessed February 17, 2021

4. State Council, Central Committee of the Communist Party of China. Guiding opinions of the General Office of the State Council on promoting the construction of hierarchical diagnosis and treatment system [in Chinese]. 2015. http://www.gov.cn/zhengce/content/201509/11/content_10158.htm. Accessed February 17, 2021

5. National Health Commission of the People's Republic of China. China health statistical yearbook 2020 [in Chinese]. Beijing: Peking union medical college publishing house, 2020.

6. Ministry of Health of the People's Republic of China. China health statistical yearbook 2010 [in Chinese]. Beijing: Peking union medical college publishing house, 2010.

7. National Health Commission of the People's Republic of China. Statistical Communique on the Development of Health and Family Planning in China in 2019 [in Chinese]. 2020. http://www.nhc.gov.cn/guihuaxxs/s10748/202006/ebfe31f24cc145b198dd730603ec4442.shtml

8. The Central people's Government of People's Republic of China. Statistical Communique on the Development of Health and Family Planning in China in 2009 [in Chinese]. 2010. http://www.gov.cn/gzdt/2010-04/09/content_1576944.htm 
9. Wang HH, Wang JJ, Wong S, Wong M, Mercer SW, Griffiths S. The development of urban community health centres for strengthening primary care in China: a systematic literature review. Br Med Bull. 2015;116(1):139-153. doi:10.1093/bmb/ldv043

10. State Council. Guidance of the state council on establishing the general practitioner system [in Chinese]. 2011. http://www.gov.cn/zwgk/2011-07/07/content_1901099.htm. Accessed February 17, 2021

11. Lian SQ, Chen Q, Yao M, Chi CH, Fetters MD. Training pathways to working as a general practitioner in China. Fam Med 2019; 51 : 262270. doi:10.22454/FamMed.2019.329090

12. Epstein RM, Hundert EM. Defining and Assessing Professional Competence. JAMA. 2002,287(2):226-235. doi:10.1001/jama.287.2.226

13. European Academy of Teachers in General Practice (Network within WONCA Europe). The European Definition of General Practice/Family Medicine. 2005. http://www.woncaeurope.org/sites/default/files/documents/Definition\%20EURACTshort\%20version.pdf. Accessed February 17, 2021

14. The College of Family Physicians of Canada. CanMEDS-FM 2017: A competency framework for family physicians across the continuum. 2017. https://www.cfpc.ca/canmedsfm/. Accessed February 17, 2021

15. The Accreditation Council for Graduate Medical Education and The American Board of Family Medicine. The Family Medicine Milestone Project. 2015. http://www.acgme.org/Portals/0/PDFs/Milestones/FamilyMedicineMilestones.pdf. Accessed February 17, 2021

16. The Royal College of General practitioners. Workplace Based Assessment囚WPBA囚competencies. 2016. https://www.rcgp.org.uk/trainingexams/mrcgp-exam-overview.aspx. Accessed February 17, 2021

17. The Royal Australian College of General Practitioners. Competency profile of the Australian general practitioner at the point of fellowship. 2015. https://www.racgp.org.au/FSDEDEV/media/documents/Education/Registrars/Fellowship\%20Pathways/FRACGP/Competencyprofile.pdf. Accessed February 17, 2021

18. Li X, Lu J, Hu S, Cheng KK, De Maeseneer J, Meng Q, et al. The primary health-care system in China. Lancet. 2017;390(10112):2584-2594. doi:10.1016/S0140-6736(17)33109-4

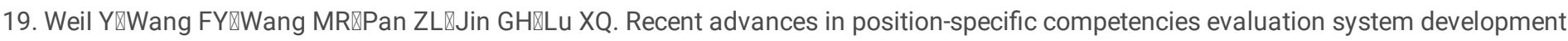
for Chinese general practitioners $₫$ Chinese General Practice $\ 2021$.『in Chinese, Epub ahead of print $₫$ doi:10.12114/j.issn.10079572.2021.00.103

20. Sumsion T. The Delphi Technique: An Adaptive Research Tool. British Journal of Occupational Therapy. 1998;61(4):153-156. doi:10.1177/030802269806100403

21. Boulkedid R, Abdoul H, Loustau M, Sibony O, Alberti C. Using and reporting the Delphi method for selecting healthcare quality indicators: a systematic review. PLoS One. 2011;6(6):e20476. doi:10.1371/journal.pone.0020476

22. Jin G, Wei Y, Liu Y, Wang F, Wang M, Zhao Y, et al. Development of type 2 diabetes mellitus quality indicators in general practice by a modified Delphi method in Beijing, China. BMC Fam Pract. 2020 Jul 19;21(1):146. doi: 10.1186/s12875-020-01215-9.

23. Gagliardi D, Rondinone BM, Mirabile M, Buresti G, Ellwood P, Hery M, et al. The perspective of European researchers of national occupational safety and health institutes for contributing to a European research agenda: a modified Delphi study. BMJ Open. 2017;7(6):e015336. doi:10.1136/bmjopen-2016-015336

24. Patterson F, Ferguson E, Lane P, Farrell K, Martlew J, Wells A. A competency model for general practice: implications for selection, training, and development. Br J Gen Pract. 2000;50(452):188-193.

25. Hasson F, Keeney S, McKenna H. Research guidelines for the Delphi survey technique. J Adv Nurs. 2000 Oct;32(4):1008-15. PMID: 11095242.

26. Chinese medical doctor association. Content and rules for Standardized Training of General Practitioners (2019 revised edition) [in Chinese]. 2019. https://www.ccgme-cmda.cn/news/home. Accessed February 17, 2021

27. Beijing Municipal Health Commission. Opinions on Accelerating the Development of Community Health Services [in Chinese]. 2000. http://wjw.beijing.gov.cn/. Accessed February 17, 2021

28. Diamond IR, Grant RC, Feldman BM, Pencharz PB, Ling SC, Moore AM, et al. Defining consensus: a systematic review recommends methodologic criteria for reporting of Delphi studies. J Clin Epidemiol. 2014;67(4):401-409. doi: 10.1016/j.jclinepi.2013.12.002.

29. Wong SYS, Lee A. Communication Skills and Doctor Patient Relationship. Hong Kong Med Diary. 2006;11(3):7-9

30. Mercer SW, Reynolds W. Empathy and quality care. Br J Gen Pract. 2002;52:S9-S12

31. Li T, Lei T, Xie Z, Zhang T. Determinants of basic public health services provision by village doctors in China: using non-communicable diseases management as an example. BMC Health Serv Res. 2016;16:42. doi:10.1186/s12913-016-1276-y

32. Li H, Liu K, Gu J, Zhang Y, Qiao Y, Sun X. The development and impact of primary health care in China from 1949 to 2015: A focused review. Int J Health Plann Manage. 2017;32(3):339-350. doi:10.1002/hpm.2435 
33. Campbell S, Kontopantelis E, Hannon K, Burke MJ, Barber A, Lester H. Framework and indicator testing protocol for developing and piloting quality indicators for the UK quality and outcomes framework. BMC Fam Pract. 2011;12(1):85. doi:10.1186/1471-2296-12-85

34. Royal College of General Practitioners. The multi-source feedback (MSF). https://www.rcgp.org.uk/training-exams/training/newwpba/msf.aspx. Accessed February 17, 2021

35. Powell C. The Delphi technique: myths and realities. J Adv Nurs. 2003;41(4):376-382. doi:10.1046/j.1365-2648.2003.02537.x

36. McGinn CA, Gagnon MP, Shaw N, Sicotte C, Mathieu L, Leduc Y, et al. Users' perspectives of key factors to implementing electronic health records in Canada: a Delphi study. BMC Med Inform Decis Mak. 2012;12:105. doi:10.1186/1472-6947-12-105

\section{Tables}

Table 1. Panel characteristics of the Delphi process $(n=28)$

\begin{tabular}{lcc}
\hline Characteristics & Frequency & Percentage (\%) \\
\hline Gender & & \\
Male & 10 & 35.7 \\
Female & 18 & 64.3
\end{tabular}

Age, years

$\begin{array}{ccc}30-39 & 4 & 14.3 \\ 40-49 & 15 & 53.6 \\ \geq 50 & 9 & 32.1\end{array}$

Professional field

GPs in CHSI $\quad 92.1$

GPs in hospital $\quad 11 \quad 39.3$

Professors in medical university $\quad 3 \quad 10.7$

Leader of CHSI $\quad 5 \quad 17.9$

Working years

$\begin{array}{lcc}<10 & 9 & 32.1 \\ \geq 10 & 19 & 67.9\end{array}$

Highest degree

$\begin{array}{lll}\text { Bachelor } & 6 & 21.4\end{array}$

$\begin{array}{lll}\text { Master } & 17 & 60.7\end{array}$

$\begin{array}{lll}\mathrm{PhD} & 5 & 17.9\end{array}$

\begin{tabular}{lcc} 
Professional title* & & \\
Middle grade title & 4 & 14.3 \\
Associate senior grade title & 6 & 21.4 \\
Senior grade title & 18 & 64.3 \\
\hline
\end{tabular}

Abbreviation: GP General practitioner; CHSI Community health service institution

*Note: medical professional titles include junior grade, middle grade, associate senior grade and senior grade titles, which are based upon work experience and research achievement of health professional

Table 2. Results of the Delphi process 


\begin{tabular}{|c|c|c|c|c|c|c|c|c|c|}
\hline \multirow[t]{3}{*}{ Competencies } & \multicolumn{4}{|c|}{ Round 1} & \multicolumn{4}{|c|}{ Round 2} & \multirow[t]{3}{*}{ Status } \\
\hline & \multicolumn{2}{|c|}{ Importance } & \multicolumn{2}{|c|}{ Feasibility } & \multicolumn{2}{|c|}{ Importance } & \multirow{2}{*}{\multicolumn{2}{|c|}{$\begin{array}{lc} & \text { Feasibility } \\
\text { Median } & \text { Agreement(7- } \\
& 9)\end{array}$}} & \\
\hline & Median & $\begin{array}{c}\text { Agreement } \\
(7-9)\end{array}$ & Median & $\begin{array}{l}\text { Agreement(7- } \\
9)\end{array}$ & Median & Agreement(7-9) & & & \\
\hline \multicolumn{10}{|l|}{ ledge and skills } \\
\hline $\begin{array}{l}1.1 \text { Be with in-depth } \\
\text { knowledge of clinical } \\
\text { medicine }\end{array}$ & 9 & $100 \%$ & 9 & $100 \%$ & 9 & $100 \%$ & 9 & $96.4 \%$ & Included \\
\hline $\begin{array}{l}\text { 1.2 Be with in-depth } \\
\text { knowledge of general } \\
\text { practice }\end{array}$ & 9 & $100 \%$ & 9 & $96.4 \%$ & 9 & $100 \%$ & 9 & $100 \%$ & Included \\
\hline $\begin{array}{l}1.3 \text { Be with in-depth } \\
\text { knowledge of public } \\
\text { health }\end{array}$ & 9 & $100 \%$ & 9 & $96.4 \%$ & 9 & $96.4 \%$ & 9 & $92.9 \%$ & Included \\
\hline $\begin{array}{l}\text { 1.4 Be with in-depth } \\
\text { knowledge of } \\
\text { rehabilitation }\end{array}$ & - & - & - & - & 8 & $92.9 \%$ & 8 & $85.7 \%$ & Included \\
\hline $\begin{array}{l}1.5 \text { Be with in-depth } \\
\text { knowledge of psychology } \\
\text { and sociology }\end{array}$ & - & - & - & - & 8.5 & $96.4 \%$ & 8 & $89.3 \%$ & Included \\
\hline $\begin{array}{l}\text { 1.6 Be equipped with the } \\
\text { skill of history taking }\end{array}$ & 9 & $100 \%$ & 9 & $92.9 \%$ & 9 & $96.4 \%$ & 9 & $96.4 \%$ & Included \\
\hline $\begin{array}{l}1.7 \text { Be equipped with the } \\
\text { skill of physical } \\
\text { examination }\end{array}$ & 9 & $100 \%$ & 9 & $96.4 \%$ & 9 & $100 \%$ & 9 & $100 \%$ & Included \\
\hline $\begin{array}{l}1.8 \text { Interpret basic } \\
\text { clinical tests and images } \\
\text { correctly }\end{array}$ & 9 & $100 \%$ & 9 & $96.4 \%$ & 9 & $100 \%$ & 9 & $100 \%$ & Included \\
\hline $\begin{array}{l}1.9 \text { Be equipped with the } \\
\text { skill of clinical operation }\end{array}$ & 9 & $100 \%$ & 9 & $96.4 \%$ & 9 & $100 \%$ & 9 & $100 \%$ & Included \\
\hline $\begin{array}{l}1.10 \text { Record electronic } \\
\text { health information (*Use } \\
\text { electronic health record } \\
\text { system effectively ) }\end{array}$ & 9 & $100 \%$ & 9 & $92.9 \%$ & 9 & $100 \%$ & 9 & $100 \%$ & Included \\
\hline \multicolumn{10}{|l|}{ Medical Services (*Patient } \\
\hline $\begin{array}{l}\text { 2.1 Manage diseases at } \\
\text { early stage presenting in } \\
\text { an undifferentiated way }\end{array}$ & 9 & $100 \%$ & 9 & $96.4 \%$ & 9 & $100 \%$ & 9 & $96.4 \%$ & Included \\
\hline $\begin{array}{l}\text { 2.2 Manage } \\
\text { simultaneously multiple } \\
\text { complaints and } \\
\text { pathologies, both acute } \\
\text { and chronic health } \\
\text { problems in the individual }\end{array}$ & 9 & $100 \%$ & 9 & $100 \%$ & 9 & $100 \%$ & 9 & $100 \%$ & Included \\
\hline $\begin{array}{l}2.3 \text { Treat patients at } \\
\text { acute, severe and } \\
\text { dangerous stages } \\
\text { (*Manage emergency } \\
\text { conditions) }\end{array}$ & 9 & $100 \%$ & 9 & $100 \%$ & 9 & $100 \%$ & 9 & $100 \%$ & Included \\
\hline $\begin{array}{l}2.4 \text { Arrange referrals to } \\
\text { specialists when } \\
\text { necessary }\end{array}$ & 9 & $100 \%$ & 9 & $92.9 \%$ & 9 & $96.4 \%$ & 9 & $92.9 \%$ & Included \\
\hline $\begin{array}{l}\text { } 2.5 \text { Ensure patient } \\
\text { safety }\end{array}$ & - & - & - & - & 9 & $100 \%$ & 9 & $92.9 \%$ & Included \\
\hline $\begin{array}{l}\text { 2. } 2.6 \text { Provide advice of } \\
\text { rehabilitation when } \\
\text { necessary }\end{array}$ & - & - & - & - & 8 & $100 \%$ & 8 & $92.9 \%$ & Included \\
\hline $\begin{array}{l}2.7 \text { Sign contracts with } \\
\text { patients (*Sign contracts } \\
\text { with patients and provide } \\
\text { continuous service) }\end{array}$ & 9 & $96.4 \%$ & 8.5 & $85.7 \%$ & 9 & $96.4 \%$ & 9 & $92.9 \%$ & Included \\
\hline $\begin{array}{l}2.8 \text { Follow-up in patients' } \\
\text { home (*Provide home visit } \\
\text { and follow-up) }\end{array}$ & 9 & $96.4 \%$ & 8 & $78.6 \%$ & 8.5 & $96.4 \%$ & 8 & $85.7 \%$ & Included \\
\hline $\begin{array}{l}2.9 \text { Provide home care } \\
\text { when necessary }\end{array}$ & 9 & $96.4 \%$ & 9 & $92.9 \%$ & 8 & $89.3 \%$ & 8 & $89.3 \%$ & Included \\
\hline
\end{tabular}


3.1 Organize health education

$\Delta 3.2$ Screen of at risk individuals for population health issues

3.3 Provide preventive care by vaccination

$\Delta \Delta$ 3.4 Provide chemoprevention care

3.5 Establish and manage the health files

3.6 Manage the care of special population in the community (elderly,

women, children

disabled, patients with

mental illness)

3.7 Manage chronic condition (*Undertake the continuing

management of chronic

health problems)

3.8 Identify and manage public health

emergencies

sunication

4.1 Listen respectfully to patient and family

(*Listen carefully to

patients and be empathy)

4.2 Explain things clearly and check for

patients and

families understanding

4.3 Discuss with

patients and

families about their health

condition and thoughts

4.4 Propose treatment

plan to patients and

families

4.5 Engage patient and family in making decision of therapy plan (*Engage patients and families in making decision of

therapy plan that reflect

the their needs, value and goals)

4.6 Communicate effectively with colleagues

4.7 Communicate effectively with stuffs in other institutions

work

5.1 Collaborate with the members in GP team

5.2 Collaborate with other colleagues

5.3 Collaborate with stuffs in other institutions

5.4 Allocate internal resources of the

institution for optimal

patient care $(*$ Allocate

resources of the

institution for optimal

patient care)

5.5 Allocate external resources of the

institution for optimal

patient care

$\begin{array}{cccc}9 & 100 \% & 9 & 89.3 \\ 8.5 & 92.9 \% & 8 & 69.9 \%\end{array}$

$3 \%$

9

$100 \%$

9

$96.4 \%$

Included

8

$92.9 \%$

$92.9 \%$

9

$92.9 \%$

$78.6 \%$

$92.9 \%$

9

$89.3 \%$

9

$92.9 \%$

9

$96.4 \%$

$96.4 \%$

Deleted

$9 \quad 100 \%$

8

(9.9\%

$96.4 \%$

9

$100 \%$

9

$100 \%$

Included

9

$100 \%$

9

$96.4 \%$

9

$100 \%$

9

$100 \%$

Included

9

$100 \%$

9

$92.9 \%$

9

$100 \%$

9

$92.9 \%$

Included

$92.9 \%$

$100 \%$

8.5

$92.9 \%$

Included

$9 \quad 100 \%$

9

$100 \%$

8.5

$92.9 \%$

$96.4 \%$

8

$85.7 \%$

Included

$100 \%$

$100 \%$

8.5

$92.9 \%$

Included

9

$96.4 \%$

$89.3 \%$

$92.9 \%$

8

$85.7 \%$

Included

9

$96.4 \%$

$96.4 \%$

8

$89.3 \%$

Included

$96.4 \%$

8

$85.7 \%$

$85.7 \%$

7

$82.1 \%$

Included

$96.4 \%$

$96.4 \%$

8

$92.9 \%$

Included

$89.3 \%$

$92.9 \%$

8

$89.3 \%$

Included

9

$78.6 \%$

$92.9 \%$

7

$82.1 \%$

Included

8

$96.4 \%$

$82.1 \%$

8

$89.3 \%$

7

$89.3 \%$

Included

8

$92.9 \%$

7

$71.4 \%$

Deleted 
5.6 Encourage community personnel and social resources to help with community health services

5.7 Mobilize community members and social resources to provide community health

services

isionalism

6.1 Adhere to the medical rules and regulations strictly

6.2 Demonstrate a commitment to patients through clinical

excellence and high

ethical standards

6.3 Adhere to patients' right to know

6.4 Adhere to

confidentiality and

privacy principles

6.5 Have the sense of responsibility

6.6 Self-adjust in the face of challenges

ttion, learning and rch

7.1 Teach students

7.2 Be engaged in practice-based learning and development

7.3 Be engaged in the continuous enhancement of their professional activities through ongoing learning

7.4 Demonstrate an understanding of the scientific principles of research

7.5 Search, navigate, and evaluate resources and

clinical practice

guidelines that are

relevant to general

practice

7.6 Participate in or conduct researches in general practice

$\begin{array}{ccccccccr}9 & 100 \% & 9 & 96.4 \% & 9 & 100 \% & 9 & 92.9 \% & \text { Included } \\ - & - & - & - & 9 & 100 \% & 9 & 89.3 \% & \text { Included } \\ 9 & 100 \% & 9 & 96.4 \% & 9 & 96.4 \% & 9 & 92.9 \% & \text { Included } \\ 9 & 100 \% & 9 & 100 \% & 9 & 96.4 \% & 9 & 96.4 \% & \text { Included } \\ 9 & 100 \% & 8 & 92.9 \% & 9 & 100 \% & 8 & 89.3 \% & \text { Included } \\ 9 & 100 \% & 8 & 78.6 \% & 9 & 100 \% & 8 & 89.3 \% & \text { Included }\end{array}$

$78.6 \%$

$92.9 \%$

8

92.9\% Included

$9 \quad 100 \%$

8

$100 \%$

$89.3 \%$

Included

$9 \quad 100 \%$

8.5

$96.4 \%$

$100 \%$

9

$100 \%$

Included

8

$96.4 \%$

8

$89.3 \%$

$89.3 \%$

7

$92.9 \%$

Included

8

$96.4 \%$

8

$89.3 \%$

8

$92.9 \%$

8

$82.1 \%$

Included

8

$89.3 \%$

8

$89.3 \%$

8

$92.9 \%$

7.5

$85.7 \%$

Included

Note: experts rated the importance and feasibility of each indicator on a 1-9 Likert scale $(1=$ not important/feasible and $9=$ very important/feasible).

$\triangle$ competencies deleted in the first round due to failure to achieve $75.0 \%$ agreement in terms of feasibility

^ competencies deleted in the first round due to experts' recommendation

-items added in the second round

(*) competencies modified in the first round

Table 3. Final competencies in the competency model for general practitioners in China 


\begin{tabular}{|c|c|}
\hline Domains & Competencies \\
\hline \multirow{11}{*}{ ledge and skills } & 1.1 Be with in-depth knowledge of clinical medicine \\
\hline & 1.2 Be with in-depth knowledge of general practice \\
\hline & 1.3 Be with in-depth knowledge of public health \\
\hline & 1.4 Be with in-depth knowledge of rehabilitation \\
\hline & 1.5 Be with in-depth knowledge of psychology and sociology \\
\hline & 1.6 Be equipped with the skill of history taking \\
\hline & 1.7 Be equipped with the skill of physical examination \\
\hline & 1.8 Interpret basic clinical tests and images correctly \\
\hline & 1.9 Be equipped with the skill of clinical operation \\
\hline & 1.10 Use electronic health record system effectively \\
\hline & 2.1 Manage diseases at early stage presenting in an undifferentiated way \\
\hline \multirow{9}{*}{ it care } & 2.2 Manage simultaneously multiple complaints, both acute and chronic health problems in the individual \\
\hline & 2.3 Manage emergency conditions \\
\hline & 2.4 Arrange referrals to specialists when necessary \\
\hline & 2.5 Ensure patient safety \\
\hline & 2.6 Provide advice of rehabilitation when necessary \\
\hline & 2.7 Sign contracts with patients and provide continuous service \\
\hline & 2.8 Provide home visit and follow-up \\
\hline & 2.9 Provide home care when necessary \\
\hline & 3.1 Organize health education \\
\hline \multirow{6}{*}{ public health services } & 3.2 Provide preventive care by vaccination \\
\hline & 3.3 Establish and manage the health files \\
\hline & $\begin{array}{l}\text { 3.4 Manage the care of special population in the community (elderly, women, children, disabled, patients with } \\
\text { mental illness) }\end{array}$ \\
\hline & 3.5 Undertake the continuing management of chronic health problems \\
\hline & 3.6 Identify and manage public health emergencies \\
\hline & 4.1 Listen carefully to patients and be empathy \\
\hline \multirow{7}{*}{ ıunication } & 4.2 Explain things clearly and check for patients and families understanding \\
\hline & 4.3 Discuss with patients and families about their health condition and thoughts \\
\hline & 4.4 Propose treatment plan to patients and families \\
\hline & 4.5 Engage patients and families in making decision of therapy plan that reflect the their needs, value and goals \\
\hline & 4.6 Communicate effectively with colleagues \\
\hline & 4.7 Communicate effectively with stuffs in other institutions \\
\hline & 5.1 Collaborate with the members in GP team \\
\hline \multirow{6}{*}{ work } & 5.2 Collaborate with other colleagues \\
\hline & 5.3 Collaborate with stuffs in other institutions \\
\hline & 5.4 Allocate resources of the institution for optimal patient care \\
\hline & 5.5 Demonstrate collaborative leadership in professional practice to enhance health care \\
\hline & 5.6 Encourage community personnel and social resources to help with community health services \\
\hline & 6.1 Adhere to the medical rules and regulations strictly \\
\hline \multirow{6}{*}{;sionalism } & 6.2 Demonstrate a commitment to patients through clinical excellence and high ethical standards \\
\hline & 6.3 Adhere to patients' right to know \\
\hline & 6.4 Adhere to confidentiality and privacy principles \\
\hline & 6.5 Have the sense of responsibility \\
\hline & 6.6 Self-adjust in the face of challenges \\
\hline & 7.1 Teach students \\
\hline \multirow{5}{*}{$\begin{array}{l}\text { ttion, } \\
\text { :ch }\end{array}$} & 7.2 Be engaged in practice-based learning and development \\
\hline & 7.3 Be engaged in the continuous enhancement of their professional activities through ongoing learning \\
\hline & 7.4 Demonstrate an understanding of the scientific principles of research \\
\hline & 7.5 Search, navigate, and evaluate resources and clinical practice guidelines that are relevant to general practice \\
\hline & 7.6 Participate in or conduct researches in general practice \\
\hline
\end{tabular}




\section{Figures}

\begin{tabular}{|c|c|c|c|c|c|}
\hline \multicolumn{2}{|c|}{$\begin{array}{l}\text { Literature review } \\
88 \text { competencies identified }\end{array}$} & \multicolumn{2}{|c|}{$\begin{array}{l}\text { Behavioral observation } \\
21 \text { competencies identified }\end{array}$} & \multicolumn{2}{|c|}{$\begin{array}{l}\text { Critical incidents interview } \\
35 \text { competencies identified }\end{array}$} \\
\hline \multicolumn{6}{|c|}{$\begin{array}{l}\text { A total of } 144 \text { competencies identified } \\
63 \text { competencies left after removal of duplicate competencies }\end{array}$} \\
\hline \multicolumn{6}{|c|}{$\begin{array}{l}46 \text { competencies left after removal of competencies difficult to measure based on a meeting with } 1 \\
\text { professor and } 4 \mathrm{PhD} \text { candidates }\end{array}$} \\
\hline \multirow[t]{3}{*}{ Round 1} & \multicolumn{5}{|c|}{$\begin{array}{l}30 \text { eligible experts were invited to participate in the study } \\
28 \text { experts (GPs, managers, and researchers) agreed to participate } \\
46 \text { competencies were rated for importance and feasibility on a 1-9 Likert scale }\end{array}$} \\
\hline & \multicolumn{2}{|c|}{$\begin{array}{l}\text { Competencies retained for Delphi } \\
\text { round } 2\end{array}$} & \multicolumn{2}{|c|}{ Not retained for round 2} & $\begin{array}{l}\text { Newly added to } \\
\text { round } 2 \\
\end{array}$ \\
\hline & $\begin{array}{l}44 \text { competencies } \\
\text { achieved } \\
\text { consensus } \\
\text { level (median } \\
\text { score }>7.00 ;> \\
75 \% \text { of panel } \\
\text { ratings in } 7-9 \text { ) }\end{array}$ & $\begin{array}{l}8 \text { competencies } \\
\text { modified based } \\
\text { on the experts' } \\
\text { comments. }\end{array}$ & \multicolumn{2}{|c|}{$\begin{array}{l}3 \text { competencies removed } \\
\text { ( } 2 \text { competencies did not } \\
\text { achieved consensus level } \\
\text { and } 1 \text { was recommended } \\
\text { to be removed by more } \\
\text { than } 2 \text { experts) }\end{array}$} & $\begin{array}{l}7 \text { competencies } \\
\text { added based on } \\
\text { the suggestion } \\
\text { by more than } \\
\text { two experts }\end{array}$ \\
\hline \multirow[t]{2}{*}{ Round 2} & \multicolumn{5}{|c|}{\begin{tabular}{|l}
28 experts (same as in round 1 ) participated in round 2 Delphi survey \\
50 competencies were rated for importance and feasibility on a $1-9$ Likert scale
\end{tabular}} \\
\hline & \multicolumn{5}{|c|}{$\begin{array}{l}50 \text { competencies achieved consensus level (median score }>7.00 ;>75 \% \text { of panel } \\
\text { ratings in 7-9) }\end{array}$} \\
\hline
\end{tabular}

\section{Figure 1}

Process of the Delphi study.

\section{Supplementary Files}

This is a list of supplementary files associated with this preprint. Click to download. 
- Table1.PanelcharacteristicsoftheDelphiprocess.docx

- Table2.ResultsoftheDelphiprocess.docx

- Table3.FinalcompetenciesforGPsinChina.docx

Page 15/15 